\title{
Spyglass Direct Visualization System facilitated management of iatrogenic biliary stricture: a novel approach in difficult cannulation
}

A 70-year-old man with a history of cholelithiasis underwent laparoscopic cholecystectomy. At a follow-up visit 2 months later, he complained of epigastric pain and weight loss. Alkaline phosphatase, $\gamma$-glutamyl transferase, and bilirubin levels were all elevated. Magnetic resonance cholangiopancreatography showed a stricture in the middle of the common bile duct and dilatation above the stricture.

The patient was referred to us for endoscopic retrograde cholangiopancreatography (ERCP), which revealed an iatrogenic stenosis of the common bile duct at the level of the junction with the cystic duct, caused by cholocystectomy clips, with dilatation of the bile ducts above that level. Attempts to advance several kinds of guide wires beyond the stricture, including Jagwire 0.035-0.025 inches (Boston Scientific, Natick, Massachusetts, USA) and angled Terumo (Terumo Europe, Leuven, Belgium), were unsuccessful because of the severe narrowing and eccentric position of the opening of the stricture due to the clip angulation, which caused the wire to advance only into the cystic duct ( $\bullet$ Fig. 1).

A decision was made to use the SpyGlass Direct Visualization System (SDVS) (Boston Scientific, Natick, Massachusetts, USA). The SDVS was introduced into the bile duct and a clear visualization of the openings of the stricture and the cystic duct was achieved ( $\bullet$ Fig. 2 ). Subsequently, the stricture was easily cannulated, dilated, and stented ( $\bullet$ Fig. 3 ).

ERCP-guided cholangiopancreatoscopy with SDVS allows direct visualization of the bile ducts, tissue sampling, and therapeutic maneuvers [ $1-3]$. Tight and eccentric strictures are a common cause of unsuccessful cannulation and ERCP failure. In such cases a second ERCP is usually attempted and, if unsuccessful, a percutaneous approach or revision surgery is usually employed. To the best of our knowledge this is one of the very few reported cases of the use of SDVS for cholangioscopic placement of a guide wire across a difficult stricture. The first reported case concerned an anastomotic stric-

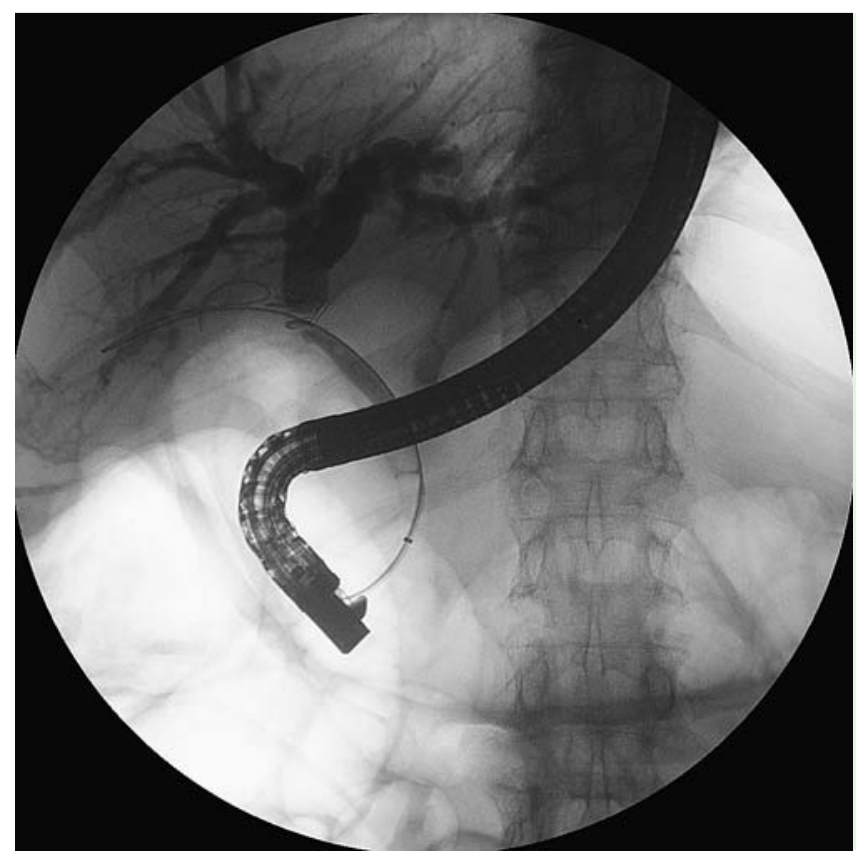

Fig. 1 Radiograph showing the tight and eccentric stricture and the guide wire in the cystic duct.

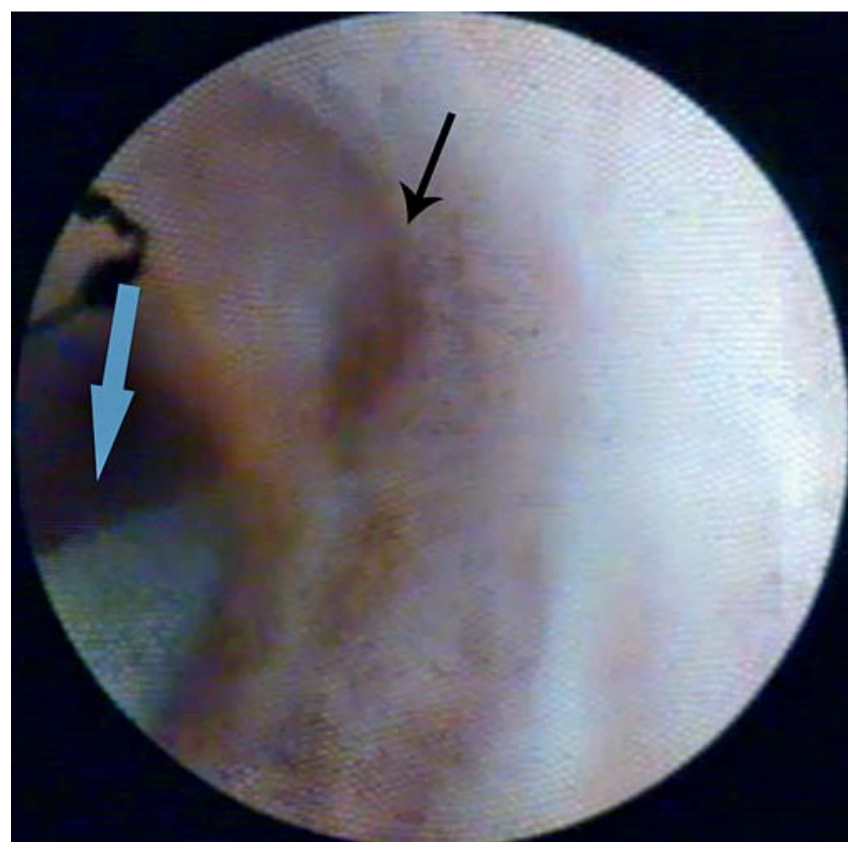

Fig. 2 SpyGlass view of the openings of the stricture cannulated with the Terumo guide wire (blue arrow) and the cystic duct (black arrow).

ture in a liver transplant recipient and the second one a patient with a hilar biliary tumor $[4,5]$. We suggest that in cases where ordinary cannulation of an iatrogenic biliary stricture fails, the use of SDVS for guided cannulation may represent an alternative, innovative and successful approach.
Endoscopy_UCTN_Code_TTT_1AR_2AG

Competing interests: None 


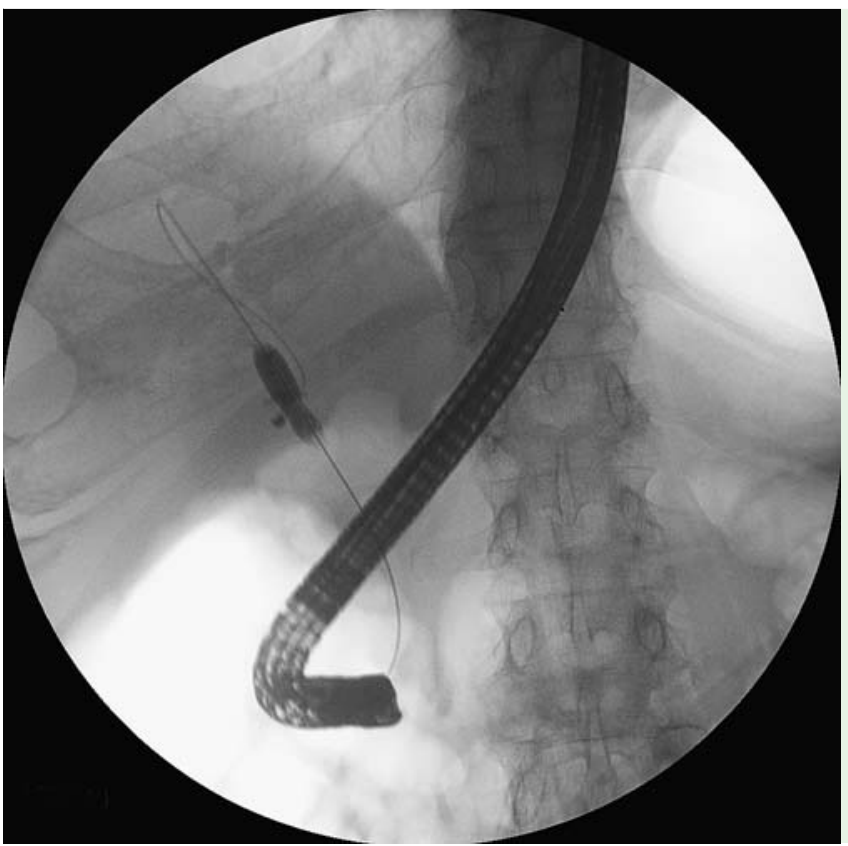

Fig. 3 Radiograph showing the biliary stenosis dilated by a balloon dilator.

\section{A. Theodoropoulou, E. Vardas, E. Voudoukis, A. Tavernaraki, G. Tribonias, K. Konstantinidis, G. A. Paspatis}

Department of Gastroentrology, Benizelion General Hospital, Heraklion, Crete, Greece

\section{References}

1 Chen YK, Pleskow DK. SpyGlass single-operator peroral cholangiopancreatoscopy system for the diagnosis and therapy of bileduct disorders: a clinical feasibility study (with video). Gastrointest Endosc 2007; 65: $832-841$

2 Chen YK, Parsi MA, Binmoeller KF et al. Single-operator cholangioscopy in patients requiring evaluation of bile duct disease or therapy of biliary stones (with videos). Gastrointest Endosc 2011; 74: 805-814
3 Draganov PV, Lin T, Chauhan S et al. Prospective evaluation of the clinical utility of ERCPguided cholangiopancreatoscopy with a new direct visualization system. Gastrointest Endosc 2011; 73: 971 -979

4 Wright H, Sharma S, Gurakar A et al. Management of biliary stricture guided by the Spyglass Direct Visualization System in a liver transplant recipient: an innovative approach. Gastrointest Endosc 2008; 67: $1201-1203$

5 Bhat YM, Kochman ML. Novel management of complex hilar biliary strictures with the Spyglass Direct Visualization System (with video). Gastrointest Endosc 2009; 69: $1182-1184$

Bibliography

Dol http://dx.doi.org/

10.1055/s-0032-1325857

Endoscopy 2012; 44: E433-E434

(c) Georg Thieme Verlag KG

Stuttgart · New York

ISSN 0013-726X

\section{Corresponding author}

G. A. Paspatis, MD

Department of Gastroenterology

Benizelion General Hospital

L. Knossou

71409 Heraklion

Crete

Greece

Fax: +30-2810-368017

paspati@admin.teiher.gr 